\title{
A Study on the Work Well-Being of Personnel in Telecommunication Marketing as Well as Its Influencing Factors in China
} -Based on the Researches in the Guangzhou Branch of China Telecom

\author{
Yuanqing Shen ${ }^{1}$, Long $\mathrm{Li}^{2}$ \\ ${ }^{1}$ Management School, Jinan University, Guangzhou, China \\ ${ }^{2}$ School of Journalism \& Communication, Jinan University, Guangzhou, China \\ Email: 283488973@qq.com
}

Received 17 January 2015; accepted 2 February 2015; published 5 February 2015

Copyright (C) 2015 by authors and Scientific Research Publishing Inc.

This work is licensed under the Creative Commons Attribution International License (CC BY).

http://creativecommons.org/licenses/by/4.0/

c) (i) Open Access

\begin{abstract}
Based on literature research and interviews, this study proposes three main Work Well-Being dimensions in line with the telecommunications marketing personnel characteristics. They are organizational commitment, overall reward and family support. Then the study builds the concept model. With data from questionnaires of $\mathbf{1 5 5}$ samples, this research analyzes the work well-being of telecommunications marketing personnel as well as its influencing factors with living examples. The results show that organizational commitment and total compensation have a significant positive correlation with work well-being, while family support is insignificantly negative correlated with work well-being. There are some factors that have more positive contribution to work wellbeing: Non-economic compensation, economic compensation, ideal expectation, social norms, economic costs, while the negative factors are emotion recognition, career opportunity, family time and family behavior.
\end{abstract}

\section{Keywords}

Telecommunication Industry, Marketing Personnel, Work Well-Being, Factors

\section{Introduction}

In recent years, the word "Happiness" has been widely known in China. The question that "Are you happy?" has been a hot topic. Various kinds of projects on "People’s Happiness Survey", and "Happiness Cities Ranking”, 
with the purpose of surveying people's happiness level, are increasing quietly. The issue about well-being, in particular the study of work well-being, has attracted many researchers' attention. By connecting work wellbeing with enterprise operation, more Chinese scholars have started to conduct researches of the influences of relevant factors on people's work well-being. As a result, some research tools and theories that conform to Chinese culture practical features have been put forward. However, there are few empirical studies. With the rapid development of China's market economy and informatization, as the important carrier in marketing, marketing service personnel has increasingly become the key to expand business market. In China's present telecommunication industry, the three state-owned communication operators, namely China Telecom, China Mobile and China Union, are competing against each other to get a bigger market share. In this process, all of them have adopted similar business line-focusing on marketing and service. Therefore, as the pacemakers in expanding market, salespersons' enthusiasm and their well-being not only have played an important role in the performance of China's telecommunication industry and its sustainable development, but have affected the realization degree of China's informatization.

\subsection{Work Well-Being}

Since 1950s, the concept of Work Well-being has increasingly attracted scholars' attention. Though there are many definitions on Work Well-being, Diener's definition is accepted widely in academic field. He defines it as: Individual's attitude on his own life and his evaluation to perception. Emotion and cognition constitute the two essential aspects of Work Well-being. Emotion is what we feel inside in our reality life both positively and negatively. Cognition, that is life satisfaction including general satisfaction and specific satisfaction, is what we feel about material life [1]. Studies conducted by foreign scholars emphasize the prominent factors that have an important effect on Work Well-being, such as character, outlook on life and self-adjustment ability.

\subsection{Knowledge Sales}

Knowledge sales not only take part in marketing of enterprise's products, but also have to be responsible for related technical work such as consulting and after-sale service [2]. knowledge sales are equipped with specialized knowledge and relatively higher education level and high position threshold. they attach more importance to work stability and its career prospects. Meanwhile, because of their professional characteristics, they usually change their jobs in the same industry.

\subsection{Testing and Evaluation on Work Well-Being}

Among various ways of evaluating Work Well-being, the usually used testing and evaluation scales include Emotion Balance Scale designed by Bradburn in 1963, Well-being Index Scale by Campbell in 1976 being used as a quantitative tool to measure people's inner well-being index , General Well-being Scale by USA State Center of Health Statistics in 1977 being used to test and evaluate people's work well-being, Life Satisfaction Scale by Diener in 1985, Multi-dimensions Well-being Scale by Ryff in 1989 [3].

\subsection{Factors Influencing Work Well-Being}

Representative researchers of Work Well-being include Warr, Horn and Ryff. The concept of employees' wellbeing was put forward by Warr in 1979, and he believed that emotional experience (like positive emotion) and cognition experience (like capability) are the main factors that affect work well-being. And his view was proved in Cifer's empirical study. Based on the formers' research achievements, Horn designed an employees’ psychological well-being questionnaire covering five dimensions, namely motivation, emotional well-being, social well-being, psychogenic physical symptoms and cognition well-being. Ryff's study is about individual's cognition on himself or surroundings, which consists of six dimensions of Work Well-being: self-independency, personal growth, environment control, positive intercourse relationship, life goals and self-acceptance [4]. While studying employees' well-being, foreign researchers focus on studying the relationships between their well-being and their work situation as well as working rules.

In China, documents about studies on the employees' well-being are very insufficient. And so far there are no relatively systemic theoretical research results. Most of Chinese scholars' studies focus on the relationships between the employees' well-being and a certain factor or several factors. Following are some typical research achievements: by using the model of work demands—work resources, X. L. Luan [5] carried out the study on 
the relationships between working characteristics, individual characteristics and work well-being with empirical approach. After interviewing 324 employees in foreign companies located in Pearl River Delta with the help of Life Quality Questionnaire, Y. L. Wei’s efforts helped her make the conclusion that subjective well-being has a positive relation with family function and characters. In the comprehensive study on factors affecting employees' work well-being, Z. J. Xing [6] believed that five main factors which affect work well-being are material satisfaction degree, self-satisfaction degree, social relationships, individual family background and organization system. B. Deng and Z. J. Ma jointed hands to create a four-factor model that influences employees’ work wellbeing, including psychological ownership, organizational commitment, work security, total compensation. Based on this, X. X. Yang [7] added the factor of family support. Y. J. Mao, J. Feng and S. Y. Bai [8] came up with the five-factor model, namely individual motive, intercourse relationships, working nature and income, organizational support and pressure.

\subsection{Theory Model}

Based on the studies by foreign and Chinese scholars and the group characteristics of sales, this research presents three work well-being dimensions of marketing personnel in telecommunications industry-organizational commitment, overall reward and family support. Many foreign and Chinese studies show that organizational commitment helps enhance employees' work well-being. Besides, both the positive emotion and positive cognition evaluation on individual have good effects on organization. The direct goal of overall reward is to improve employees' satisfaction degree so as to attract more excellent employees to stay in the company. Its value lies in balancing the benefits between enterprise and employees, and enhancing both enterprises' performance and employees’ satisfaction degree so that employees' work well-being can be strengthened. As for family support, we only select the dimension of family's influence on work in the work-family conflict, and then to find out how family factor affects employee's work well-being. The study indicates that work-family conflicts will result in some phenomena, such as employee's failing performance, being late, absence from work and lower work well-being.

\section{Study Design}

\subsection{Sampling}

The valid return rate of this research is $81.579 \%$ with 190 distributing questionnaires and 155 returned valid ones in each Marketing and Service Centers of China Telecom in Guangzhou.

\subsection{Scale Design}

Based on the main studies at home and abroad and interviews before this research, as well as sales group characteristics, this research presents three work well-being dimensions of telecommunications industry marketing personnel-organizational commitment, overall reward and family support. At the same time, there are 10 second class indexes including emotion recognition, social norms, ideal expectation, economic costs, career opportunity, economic compensation, non-economic compensation, family time, family pressure and family behavior. The organizational commitment scale is designed by making reference to both the three-factor modelemotion, proceeding, norms by Canadian scholars Meyer and Allen, and Chinese enterprises employees’ organizational commitment five-factor model, including 12 items [9]. And overall reward, including 6 items, is mainly based on the overall reward scale designed by F. Wen in 2006. The design of family support scale, including 6 items, is learned from the work-family conflict scale by Williams, Michelle and others.

\subsection{The Check of Reliability of the Questionnaire}

In empirical study, Cronbach's $\alpha$ coefficient method is often applied to test the reliability of the study and the reliability coefficient between from 0.8 to 0.9 is regarded as acceptable. Analyzed with SPSS17.0, the alpha coefficient of the questionnaire is 0.889 , showing that the questionnaire is reliable and the result is effective.

\section{Data Analysis}

\subsection{Description of the Sample Statistics}

As we can see from the Table 1 , determined by the characteristics of telecom marketing service work, male 
Table 1. Description of the sample statistics.

\begin{tabular}{|c|c|c|c|c|c|}
\hline Subject & Variable Value & Percentage (\%) & Subject & Variable Value & Percentage (\%) \\
\hline Sex & $\begin{array}{c}\text { Male } \\
\text { Female }\end{array}$ & $\begin{array}{l}64.5 \\
35.5\end{array}$ & Age & $\begin{array}{c}\text { Below } 30 \\
30-39 \\
40-49 \\
50 \text { or above }\end{array}$ & $\begin{array}{c}41.9 \\
43.2 \\
14.2 \\
0.7\end{array}$ \\
\hline $\begin{array}{c}\text { Education } \\
\text { Background }\end{array}$ & $\begin{array}{c}\text { High School } \\
\text { (Secondary School) or below } \\
\text { Junior College } \\
\text { Bachelor Degree } \\
\text { Graduate Degree }\end{array}$ & $\begin{array}{c}5.8 \\
7.7 \\
73.0 \\
13.5\end{array}$ & $\begin{array}{l}\text { Length } \\
\text { of Service }\end{array}$ & $\begin{array}{c}5 \text { years or below } \\
6 \text { - } 9 \text { years } \\
10-14 \text { years } \\
15 \text { - } 19 \text { years } \\
20 \text { years or above }\end{array}$ & $\begin{array}{c}43.2 \\
21.3 \\
13.5 \\
9.7 \\
12.3\end{array}$ \\
\hline $\begin{array}{c}\text { Annual } \\
\text { Income } \\
\text { (yuan) }\end{array}$ & $\begin{array}{c}\text { Below } 60,000 \\
60,000-90,000 \\
100,000-140,000 \\
150,000-190,000 \\
200,000-240,000 \\
250,000-290,000 \\
300,000 \text { or above }\end{array}$ & $\begin{array}{c}9.7 \\
25.8 \\
31.6 \\
14.8 \\
11.0 \\
4.5 \\
2.6\end{array}$ & Position & $\begin{array}{c}\text { Cluster Manger } \\
\text { Channel Manager } \\
\text { Personnel of Technical Support } \\
\text { Supervisor/Executive }\end{array}$ & $\begin{array}{l}43.2 \\
27.2 \\
13.5 \\
16.1\end{array}$ \\
\hline Martial Status & $\begin{array}{c}\text { Married } \\
\text { Unmarried }\end{array}$ & $\begin{array}{l}63.9 \\
36.1\end{array}$ & & & \\
\hline
\end{tabular}

employees account for $64.5 \%$ in all the employees investigated in the marketing center. At the same time, employees below 40 is $85 \%$, showing that the working team in China Telecom is getting younger. In addition, the table displays that employees investigated with the bachelor's degree or master's degree or above account for $73.0 \%$ and $13.5 \%$ in the team respectively, indicating that the sales team of China Telecom has high education and professional knowledge. On the other hand, more than half of the employees have worked over 5 years in the company now, so the staff has a high loyalty towards the China Telecom, a phenomenon shaped by the characteristics of the big state-owned enterprises. As for the income investigation, the overall income level of the employees in marketing center is rather high. In fact, persons with income below 60,000 yuan is only 9.7\%, while those with an income between 100,000 and 140,000 yuan is $31.6 \%$, accounting for the largest part in the all employees investigated. In the members of the marketing center, cluster managers account for nearly half of the employees while the composition ratio of channel managers, personnel of technical support or management is at common level in sales teams of telecom. In the survey, married employees is 63.9\%, which is higher than the percentage of unmarried ones, 36.1\%.

\subsection{Analysis of the Average Value in the Dimensions of Work Well-Being}

According to the result of the survey, the overall work well-being value of the employees in the marketing team of telecom industry is a little better than the medium level, but values are diverse in different dimensions of work well-being: the comprehensive compensation is 3.83, organizational commitment 3.43 and family support 2.87. Overall average salary is high, largely due to the contribution made by economy (3.78) and the economical compensation (3.88). On the contrary, low emotional recognition (3.36) and career opportunities (3.17) leads to the low average value of the organizational commitment. The average value of family support ranks the lowest because of the low average values of family time (3.16) and family activities (2.10). According to the two grade index evaluation, the value of non-financial compensation ranks first, followed by the value of financial compensation, ideal expectation, social norms and economic costs.

According to this data analysis, the employees don't have a strong sense of belonging to the company and have limited opportunities to search for another job. Besides, the employees don't invest much time in family and show little support for the family activities, making the biggest cause of the low value of work well-being. On the other hand, the high value of total compensation proves the efficiency of the organizational system of the performance evaluation of the sales team and quantifying of work in China Telecom company. The marketing center of China Telecom applies the responsibility system of index and at the same, rewards the employees with bonus matched with their performance, which is a goal stimulating the marketing staff to work better. 


\subsection{Analysis of the Work Well-Being}

Pearson correlation coefficient is widely used in the empirical study, it can measure the linear relationship between variables. This study applies SPSS17.0 to analyze the correlation of three variables. The results shows work well-being, organizational commitment and total compensation have a highly positive correlation; family support is insignificantly negative correlated with organizational commitment; while family support has a insignificant negative correlation with total compensation and well-being.

It's easy to see that the higher organizational commitment and the total compensation are, the higher the value of work well-being sales personnel get in China Telecom. Family support is significantly negative correlated with organizational commitment for that family support is not subordinate to organizational commitment and that if family factors gets better, it doesn't necessarily mean the organizational commitment would become better as well. Actually the external factors of "family" and "organization" have little intersection. On the other hand, family support has a insignificant negative correlation with total compensation and well-being. In this study, family support is negative correlated with the work well-being of marketing personnel, showing the employees investigated in the survey bears negative influence from the factors of family time, pressure, effective conduct on their work well-being. At the same time, we have to make it clear here that the conclusion which shows family support has no positive effect on work well-being is one-way, and whether the work well-being will affect the family is still wait to be studied.

\section{Conclusion and Suggestions}

Based on 155 questionnaires, this study analyzes the work well-being and other effecting factors with the method of average values and their correlation. The conclusion is: Firstly, work well-being, organizational commitment and total compensation have a highly positive correlation while family support is insignificantly negative correlated with organizational commitment; Secondly, the work well-being of marketing personnel in China Telecom is above average and the ranking of the three dimensions from high to lower is total compensation, organizational commitment and family support; Thirdly, non-financial compensation, financial compensation, ideal expectation, social norms and economic costs have made much contribution to the work well-being of employees, on the contrary, the factors of emotional recognition, job opportunities, family time and family activities have pulled down the work well-being.

Improving the work well-being of marketing personnel in telecom industry is crucial for the development of informationization of China. To enhance the work well-being of employees, here are some suggestions:

Firstly, making good use of the company's advantages to improve sense of belonging of the staff. China Telecom has advantages on its brand strength, abundant resource of knowledge and clients and thorough professional title assessment system. Applying these advantages will help the employees to hold a stronger sense of belonging and emotion towards the China Telecom. At the same time, the company should provide training courses and career personal developing classes to the staff, help the employees with their career promotion plans and thus the employees would bear strong confidence and a sense of belonging to the company, which makes up the job security and work well-being. In this way, the staff and China Telecom would get win-win results.

Secondly, establishing fair and reasonable personnel management system and salary system. Under the principles of "equal pay for equal work" and "fair treatment", unreasonable promotion restriction should be canceled and employees at different posts shall get their fair benefits. At the same time, more employee turnover is recommended in the company. For those who are assessed as qualified should be permitted to take the job rotation in different post. The problem of over-staffing should be avoided and increasing flexibility of personnel management should be stressed to achieve better working performance.

Thirdly, giving some thoughts to the different needs of employees. Compensation and benefit policy should be made in accordance with the career development of marketing personnel in telecom industry. The company should satisfy its employees' needs in different aspects and pay more attention to the new employees, senior workers and cluster managers. Set an acceptable expectation for these workers and improve their satisfaction of salaries as much as possible.

Fourth, showing humanistic care to the staff with the characteristics of China Telecom. For example, please give some special price on telecom communication to the families of the staff as a benefit; organize some staff activities opened to the workers' families, thus giving the employees opportunities to spend time with family and enjoy various activities as well, which benefits the team building; moreover, send some blessing messages 
to workers and their families and so on. This suggestion is aimed to improve the work well-being of the staff with family support as a tool.

\section{References}

[1] Diener, E. (1984) Subjective Well-Being. Psychological Bulletin, 95, 542-575. http://dx.doi.org/10.1037/0033-2909.95.3.542

[2] Jin, H.B. (2009) The Present Situation of Knowledge-Based Sales Personnel and Stimulating Strategies. Journal of Liaoning Technical University (Social Science Edition) in China, 11, 608-610.

[3] Wang, J.Y. and Hu, A.A. (2006) Comments on Subjective Happiness Studies. Foreign Economics \& Management, No. 8, 49-55.

[4] Ryff, C.D. and Dinger, B.H. (2006) Best News Yet on the Six-Factor Model of Well-Being. Social Science Research, 35, 1103-1119. http://dx.doi.org/10.1016/j.ssresearch.2006.01.002

[5] Luan, X.L. (2008) Studies on the Correlation of Individual Characteristics, Job Characteristics and Work Well-Being. Master's Thesis, Dalian University of Technology, Dalian.

[6] Xing, Z.J. (2002) Studies on Subjective Happiness: The Empirical Exploration on Happiness. Chinese Theory Journal, No. 5, 57-60.

[7] Yang, X.X. (2009) The Studies of the Influencing Factors of the Well-Being of Employees in Enterprises-Taking the Enterprises in Beijing and Pangjin for Examples. Master's Thesis, Jilin University, Changchun.

[8] Mao, Y.J., Feng, J. and Bai, S.Y. (2009) Overview of Work Well-Being. Economic Management Journal, No. 10, 179186.

[9] Ling, W.Q., Zhang, Z.C. and Fang, L.L. (2000) Research on the Model of Chinese Employee’s Organizational Commitment. Journal of Management Sciences in China, No. 2, 76-80. 
Scientific Research Publishing (SCIRP) is one of the largest Open Access journal publishers. It is currently publishing more than 200 open access, online, peer-reviewed journals covering a wide range of academic disciplines. SCIRP serves the worldwide academic communities and contributes to the progress and application of science with its publication.

Other selected journals from SCIRP are listed as below. Submit your manuscript to us via either submit@scirp.org or Online Submission Portal.
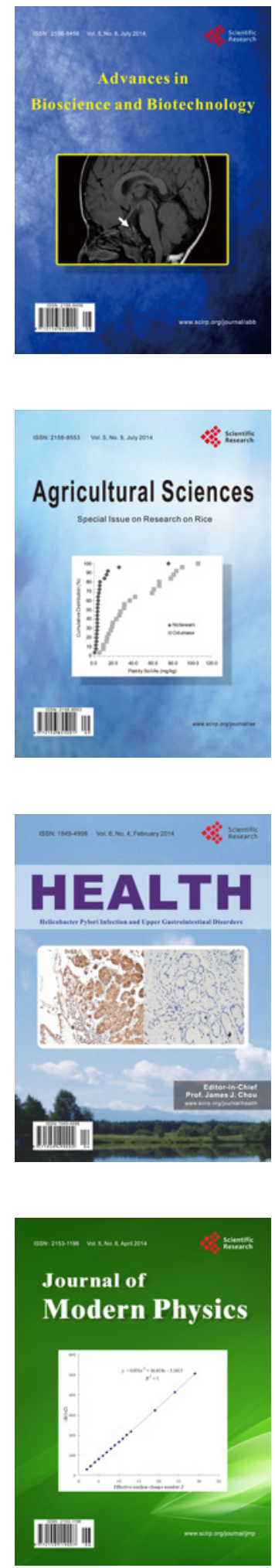
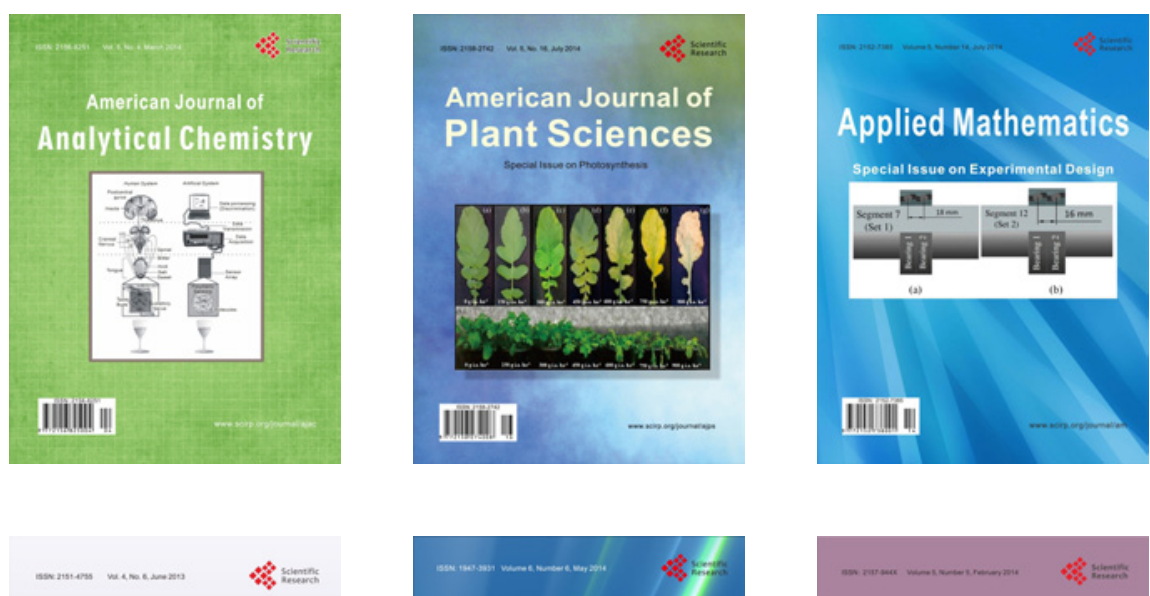

Creative Education
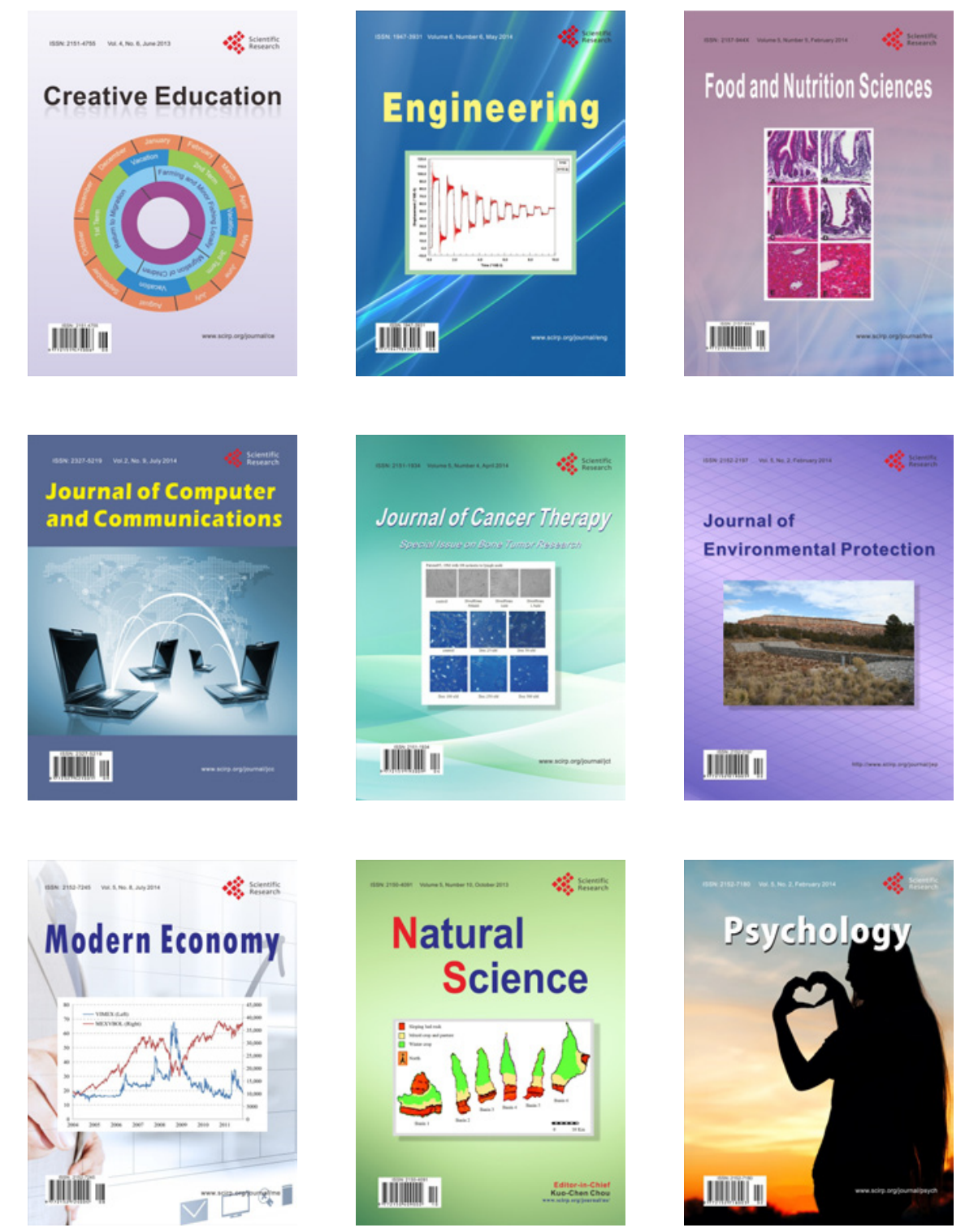